\title{
The Effect of Gender Equality on International Soccer Performance
}

\author{
Julia Bredtmann ${ }^{1,2}$, Carsten J. Crede ${ }^{3}$, and Sebastian Otten ${ }^{1,4}$ \\ ${ }^{1}$ RWI-Leibniz Institute for Economic Research \\ ${ }^{2}$ IZA \\ ${ }^{3}$ University of East Anglia \\ ${ }^{4}$ University College London
}

Julia Bredtmann is a postdoctoral researcher at RWI-Leibniz Institute for Economic Research. Her research interests cover labor economics, migration economics, and education economics.

Carsten J. Crede is a $\mathrm{PhD}$ student at the Centre for Competition Policy and the School of Economics at the University of East Anglia. His research interests include industrial organization and applied econometrics.

Sebastian Otten is a postdoctoral researcher at the Centre for Research and Analysis of Migration (CReAM) at University College London (UCL). His research interests cover labor and migration economics.

\section{Abstract}

In this article, we propose a new estimation strategy that draws on the variation in the performance between the male and the female national soccer team within a country to identify the effect of gender equality on women's soccer success. For this, countryyear fixed effects are used to control for both time-constant and time-variant countryspecific factors. Our results reveal that within-country differences in our proxies for gender equality explain the international soccer performance of female teams, but have no notable explanatory power for the success of male teams. This suggests that gender equality is an important determinant of female sport success.

Keywords: international sport success, soccer, gender equality, fixed-effects estimation

\section{Introduction}

In recent years, the equalization of political rights and economic opportunities of males and females has become a major goal of national and international policies (see, e.g., United Nations, 2015). Besides the fact that the achievement of gender equality is a worthy goal in itself, policymakers see it as a measure to accelerate economic development. This view is supported by the economic literature that has provided strong evidence for a positive correlation between the degree of gender equality within society and a country's level of economic development (see, e.g., Doepke et al., 2012; 
Duflo, 2012). In this article, we explore a different aspect of gender equality and investigate its effect on women's international soccer performance.

Major sporting events such as the Olympic Games and World Championships attract enormous attention and thereby affect public sentiment. In this regard, the performance of the national soccer teams is of particular interest, as soccer is considered to be the most popular sport worldwide. About 270 million people (i.e., $4 \%$ of the world's population) are actively involved in soccer (FIFA, 2007). The 2010 FIFA World Cup final, for example, had an average television audience of 530.9 million (FIFA, 2010), exceeding the 2015 Super Bowl by more than 415 million viewers (NBC, 2015), which renders it the most watched single sporting event. ${ }^{1}$ Due to its high popularity, a growing body of literature is concerned with the determinants of international soccer success.

Starting with Hoffmann et al. (2002) and followed by Torgler (2004), Gelade and Dobson (2007), Macmillan and Smith (2007), and Leeds and Leeds (2009), this research has shown that a country's wealth, its sports culture, and its climate have a significant impact on its strength in international soccer. These results are similar to those of studies of the determinants of Olympic success (see, e.g., Bernard and Busse, 2004; Hoffmann et al., 2004; Johnson and Ali, 2004; Trivedi and Zimmer, 2014).

In both the literature on soccer and the Olympics, empirical evidence on the determinants of women's performance is still scarce. The few studies that do exist (see Hoffmann et al., 2006; Torgler, 2008; Matheson and Congdon-Hohman, 2011; and Cho, 2013 for soccer and Klein, 2004; Leeds and Leeds, 2012; Bredtmann et al., 2016; and Lowen et al., 2016 for the Olympic Games) generally rely on the analysis of correlations between proxies for women's empowerment and their sports performance, thereby providing evidence that female performance in sports is associated with their economic opportunities and their political rights. However, as these studies are not able to control for all relevant impact factors, the identified associations might be biased by unobservable country-specific characteristics that affect both female soccer performance and women's empowerment. This article contributes to the literature by using an innovative estimation strategy to identify the effect of gender equality on the performance of female national soccer teams in international competitions.

We propose an estimation strategy that uses the variation in the performance between the female and the male national soccer team within each country. By applying this strategy, it is possible to include country-year fixed effects into the estimation model and thus control for any country-specific factors that potentially bias the estimation results. As we suspect gender equality to be one of the main reasons for differences in the international soccer performance of male and female teams coming from the same country, we use gender-specific labor force participation rates and life expectancies as proxies for differences in the economic opportunities and social integration of men and women within a country. By using gender-specific proxy variables we are able to net out all other country-specific factors that affect the performance of both male and female soccer teams.

Our results reveal that the effect of gender equality on international soccer performance differs largely between male and female teams. While within-country variation in labor force participation rates and life expectancies between the genders explains the international soccer performance of female teams, it has no notable explanatory power 
for the success of male teams. This suggests that gender equality is an important determinant of female sport success.

\section{Data and Descriptive Statistics}

Our analysis is based on the FIFA World Ranking, a ranking system that reflects the current comparative strength of men's and women's national teams in association football. Since December 1992, the International Federation of Association Football (FIFA) awards points to the member nations' male teams based on the results of their international matches played against other national teams. These points are used to calculate the ranking, with the most successful team being given a rank of one. In 2003, FIFA launched the FIFA World Ranking for women's national teams. ${ }^{2}$

In our analysis of the international success of male and female soccer teams, we use both the points awarded to a national team and its position in the FIFA Ranking as outcome variables to measure the strength of a nation's male and female soccer team, respectively. Regarding the use of the awarded FIFA points, it is important to acknowledge the fact that the distribution of points varies between the male and the female ranking procedures. While this difference in distributions does not impose a problem for the separate analysis of male and female soccer performance, it does so for the joint analysis of both genders' sports success. In order to address this issue, we use two different point measures. First, in the separate estimation models for male and female teams, we use the original FIFA points (FIFA points) as an outcome variable. ${ }^{3}$ Second, in the models in which we estimate the performance of male and female teams together, we normalize the FIFA points for each year and by gender. We then use the resulting variable Normalized FIFA points as our outcome measure to facilitate the direct comparison of male and female teams' performance.

In addition to the FIFA points, we use a team's position in the FIFA Ranking as a measure of its sports success. In doing so, we limit the sample to nations that compete with both male and female teams in international soccer competitions for any year between 2003 and 2014. This prevents a potential bias resulting from the lager number of men's than of women's national teams in the ranking to affect the results. While the restricted sample might be a selective sample of all countries, this selectivity does, if anything, result in an underestimation of the true effect of gender equality on international soccer performance, as those countries exhibiting the highest gender inequality (i.e., countries in which women do not engage in soccer, and probably in other sports, at all) have been excluded. For this sample, we construct new male and female rankings based on the teams' FIFA points for any given year. The resulting variable, Adjusted rank, serves as our third outcome measure.

Figure 1 displays the countries' international soccer performance as measured by Adjusted rank for both male and female national teams. The solid line at an angle of $45^{\circ}$ indicates a perfect correlation of men's and women's ranking, meaning that both teams perform equally well in international soccer. Countries in which the female national team is ranked higher than the male national team are located below the line and countries in which the male team outperforms the female team are located above the line. For example, Canada (CAN) is located below the line, indicating that Canada's female national team is ranked higher (8th) than its male team (101st). Figure 1 reveals that only a few countries are located around the $45^{\circ}$ line, whereas in 
most countries, there are large differences between the FIFA Ranking and the performance of male and female national soccer teams, respectively. This indicates that some country-specific conditions must exist that affect the international soccer performance of men and women differently.

In the analysis of the international soccer performance of men and women, we control for a selection of socioeconomic variables, which have either been established as important determinants of success in the previous literature or are meant to control for factors specific to female or male success, respectively. Among the general indicators are In GDP per capita and In Population, the natural logarithms of GDP per capita income and the population, which measure a country's wealth and its population size, respectively. While the population size represents the size of the available talent pool, GDP influences its development (i.e., wealthier countries have more resources to spend on health care, training facilities, and other productivity enhancing inputs). Both factors - the size and the development of talent pools-are mandatory for international soccer performance. We further take into account the effect of climate by including an indicator variable Tropics, which takes the value of 1 if more than $50 \%$ of a country's population live in tropical or subtropical climate zones, and 0 otherwise. As Sachs (2001) points out, countries that are subject to a tropical climate are suffer-

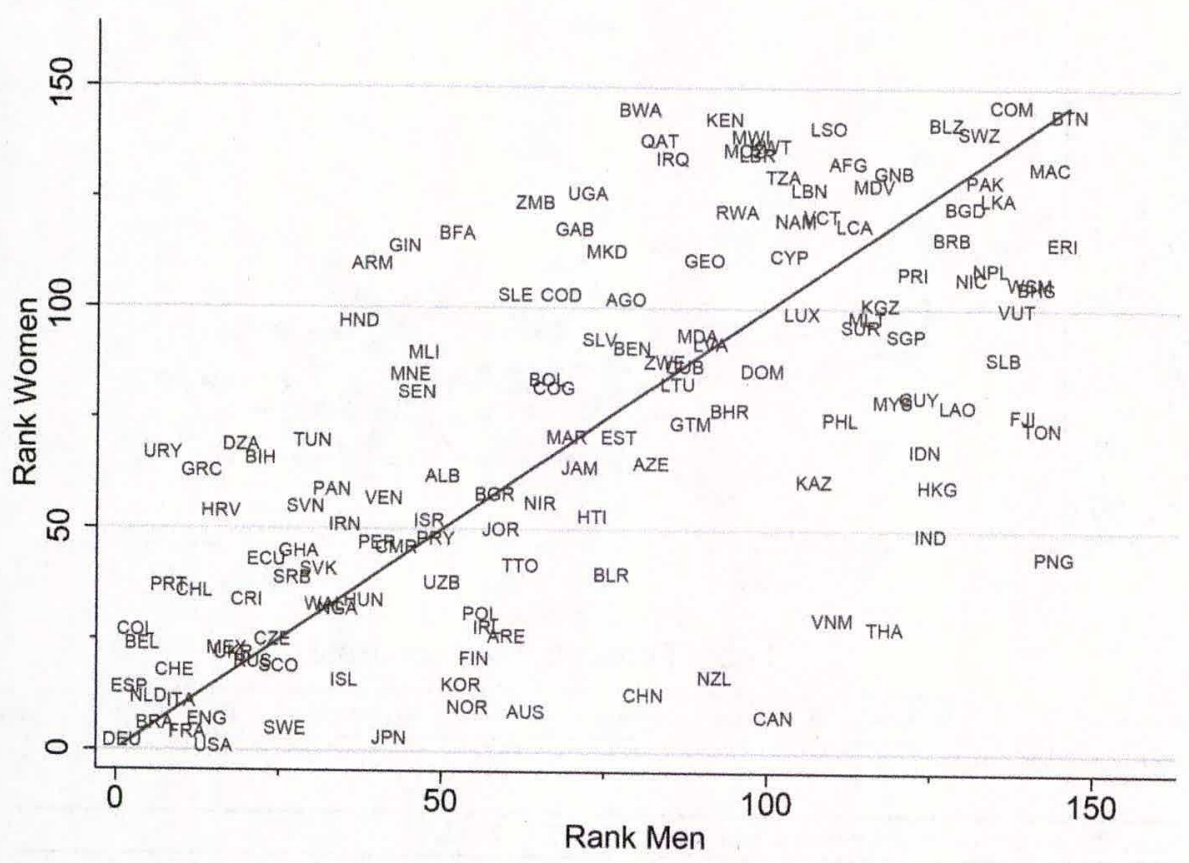

Figure 1. Ranking of national soccer teams by gender in 2014.

Notes: This figure depicts the correlation between the performance of the countries' male and female soccer teams as measured by their respective position in the FIFA Ranking 2014. The countries are represented in the figure by their ISO 3166-1 codes. The $45^{\circ}$-line indicates a perfect correlation between the ranking of male and female teams. 


\section{Bredtmann, Crede, Otten}

ing from a high burden of tropical diseases, which negatively affects a wide range of factors, including economic growth and human capital. Finally, a country's affinity toward soccer and the development of its soccer institutions affect the national team's performance. To incorporate these effects in our analysis, we follow Leeds and Leeds (2009) and control for the number of years since a nation's soccer association becomes a FIFA member. A long membership is an indicator for a high level of the soccer institutions and the importance of soccer in a country's society.

While the previously named country-specific conditions are assumed to affect both men and women, we further control for gender-specific conditions of the country. In particular, we search for variables that capture the degree of gender equality in a country's society and are therefore able to explain the differing performance of male and female soccer teams coming from the same country. We expect that countries with a low level of gender equality (i.e., societies in which women are disadvantaged or discriminated against) offer worse training facilities and less talent scouting and development for women compared to men. This does not only apply to particular traditional and conservative societies existing in many developing countries as, for example, in the

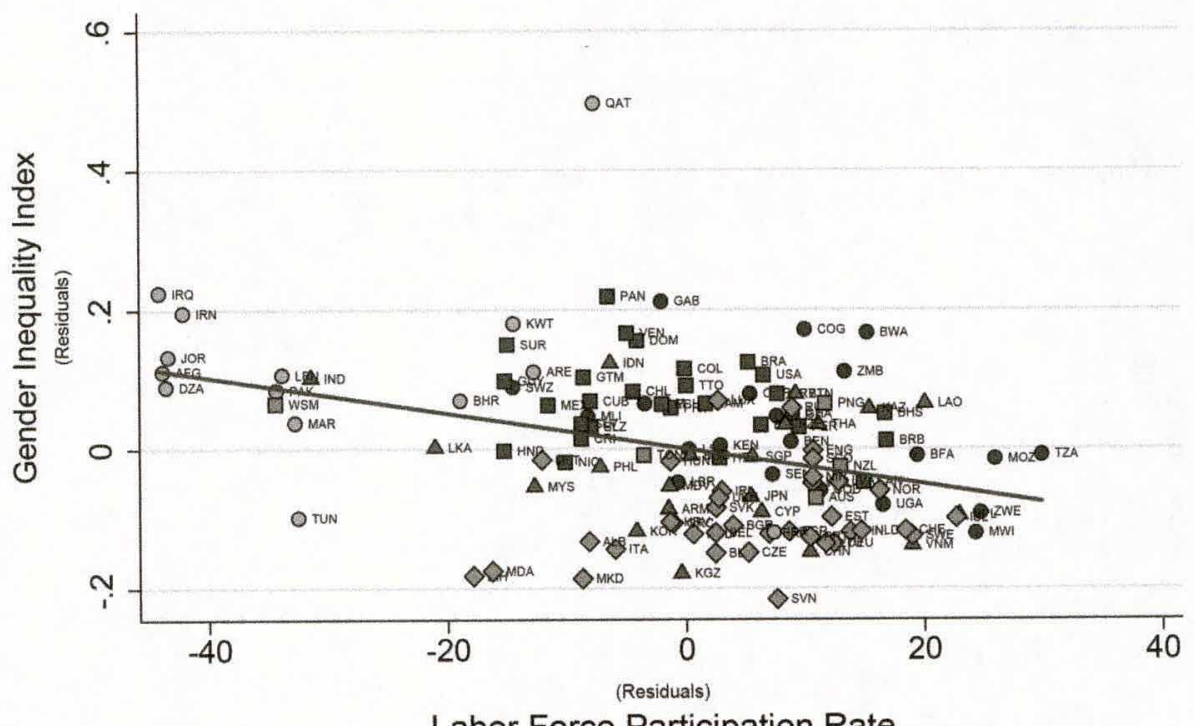

Labor Force Participation Rate

\[ \text { Africa } \text { Americas } \triangle \text { Asia } \diamond \text { Europe } \bigcirc \text { Middle East } \square \text { Oceania } \]
$($ Coef. $=-0.003$, t-stat. $=-5.48, N=127)$

Figure 2. Gender Inequality Index and Female LFPR in 2013.

Notes: This figure depicts the partial correlation between the countries' Gender Inequality Index and the Female LFPR in 2013, conditional on log GDP per capita. It shows an added-variable plot of residuals against residuals, that is, the horizontal and vertical axes plot the residuals obtained from regressing the Female LFPR and the Gender Inequality Index, respectively, on log GDP per capita. The relationship is estimated using a least-squares fit. 
Middle East and North Africa, but even in the modern Western societies, in which significant differences in the amount of sport sponsorship for men and women exist. This gender-specific inequality is expected to lead to an underperformance of female athletes relative to male athletes within a given country.

Our first variable of interest is the countries' gender-specific labor force participation rate $(L F P R)$, which approximates the economic opportunities of the population, which in turn positively affect participation in leisure activities such as competitive sports. A high difference in male and female LFPR suggests that women and men do not have the same opportunities in the labor market and thus reflects a low degree of gender equality. Indeed, as depicted in Figure 2, there exists a negative relationship between the countries' gender equality and the Female LFPR. Specifically, the plot shows the partial correlation between the countries' Gender Inequality Index (GII) and the Female $L F P R$, conditional on log GDP per capita. ${ }^{4}$ The results provide evidence for a strong negative correlation between the GII and the Female LFPR (coef. = -0.003 , t-stat. $=-5.48$ ), suggesting that the Female $L F P R$ is an adequate proxy variable for a country's gender equality.
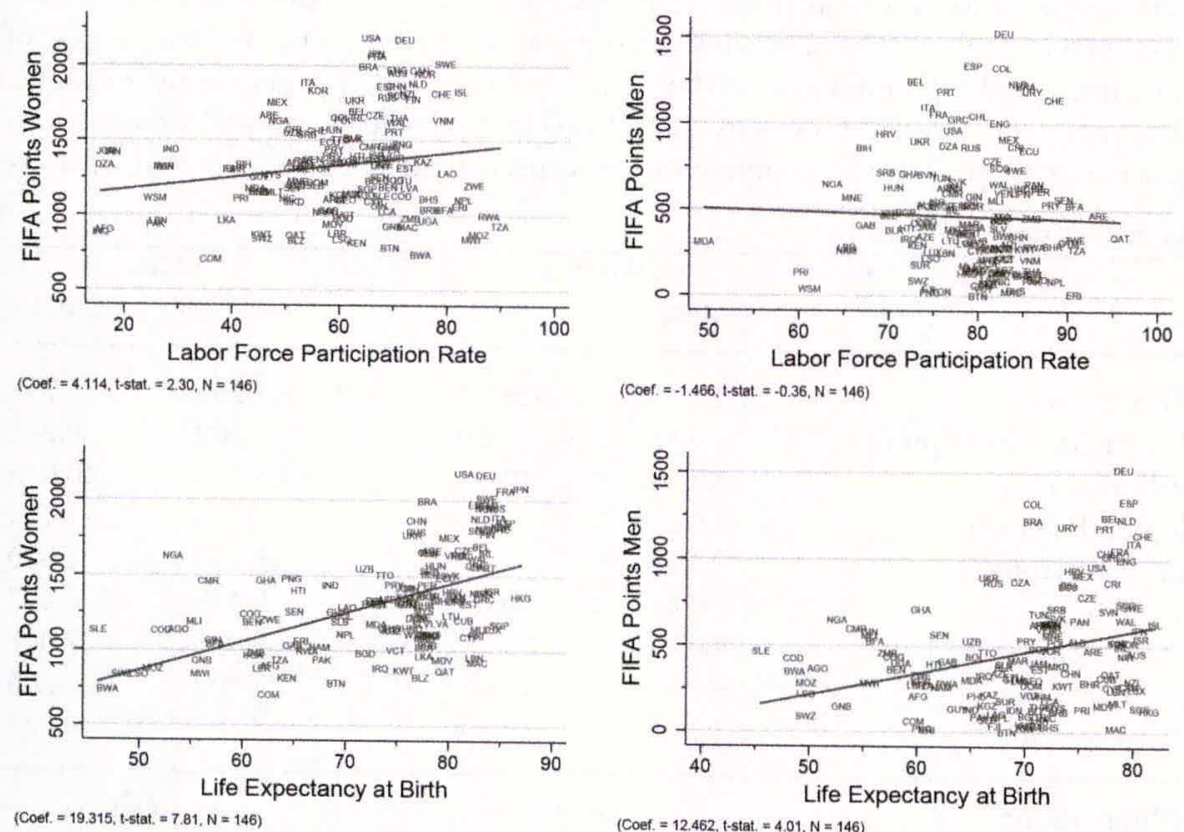

(Coef. $=12.462$, t-stat. $=4.01, N=146$ )

Figure 3. Women's and men's FIFA points and LFPR and Life expectancy in 2014.

Notes: The figure depicts the unconditional correlation between the FIFA points of the countries' male and female soccer teams and their gender-specific labor force participation rates and life expectancies, respectively, for the year 2014. The respective relationship is estimated using a least-squares fit. The countries are represented in the figure by their ISO 3166-1 codes. 
As a second measure of gender equality in the population, we use the gender-specific Life expectancy at birth, which does not only capture the overall burden of disease of a population and the quality of the health care system, but also the relative access of the genders to it. Both LFPR and Life expectancy measure the degree of emancipation and equality in society and should thus capture the same variation in the soccer performance of men and women. Therefore, the two variables are not included in a single regression, but separate regressions are estimated for both variables to ensure identification of the gender equality effect.

Figure 3 displays the relationship between the FIFA points of the countries' male and female soccer teams and their gender-specific labor force participation rates and life expectancies, respectively. For female teams, both measures of gender equality are strongly and positively correlated with their FIFA points. For male teams, in contrast, the finding is mixed; while a positive relationship exists between men's life expectancy and their FIFA points, no such relationship or even a slight negative correlation is found between their labor force participation rate and their FIFA points. This provides some first indication that LFPR and Life expectancy might contribute to the international soccer performance of female teams, but not of male teams.

The final data set contains 3,208 observations, equally divided into male and female teams, of 157 countries covering the years 2003 to 2014 . Descriptive statistics of all variables included in our analysis, separately for the male and the female sample, are displayed in Table 1. The table shows that the average FIFA points and the average of the normalized FIFA points are higher in the female sample than in the male sample, illustrating the different procedures used to award points for men's and women's success in international soccer competitions. As expected, the statistics show that, on aver-

Table 1. Descriptive Statistics

\begin{tabular}{lrrrr}
\hline & \multicolumn{2}{c}{ Women } & \multicolumn{2}{c}{ Men } \\
& Mean & \multicolumn{1}{c}{ StdD } & Mean & \multicolumn{1}{c}{ StdD } \\
\hline FIFA points & $1,383.228$ & 329.971 & 491.237 & 301.791 \\
Normalized FIFA points & 0.485 & 0.210 & 0.369 & 0.241 \\
Adjusted rank & 68.216 & 40.066 & 68.235 & 40.075 \\
ln (GDP per capita) & 9.214 & 1.144 & 9.214 & 1.144 \\
ln (Population) & 15.970 & 1.810 & 15.970 & 1.810 \\
Tropics & 0.418 & 0.493 & 0.418 & 0.493 \\
FIFA member (in years) & 60.946 & 29.067 & 60.946 & 29.067 \\
LFPR & 59.149 & 15.005 & 78.900 & 6.862 \\
Life expectancy & 73.183 & 10.336 & 68.265 & 9.087 \\
\end{tabular}

Observations

1,604

1,604

Notes: Values are based on the pooled sample over all years. The slight difference in the average rank of male and female teams is due to the possibility that two teams achieve the same number of points in a given year and are thus given the same rank in the respective year, leading the distribution of the rank of the male and the female national teams to slightly diverge from each other. The difference of means in LFPR and Life expectancy between women and men is statistically significant at the $0.1 \%$ level. 
age, men's LFPR is significantly higher and their life expectancy is significantly lower than those of women. The mean values of our control variables (GDP per capita, Population, Tropics, and FIFA member) do not differ between the male and the female sample, as they are the same for both men and women within one country. A detailed description of the variables and their data sources can be found in Table Al.

\section{Empirical Strategy}

Our empirical analysis is divided into two steps. In the first step, we regress the outcome measures FIFA points and Adjusted rank on the set of socioeconomic variables and the gender equality proxies described previously to examine the determinants of the international soccer performance separately for male and female national teams. Such an approach is standard in the literature and serves as a preliminary analysis for our main estimations of the effect of gender equality on international soccer performance carried out in the second step. Letting the indices $i$ and $t$ denote the country of the national team and the year, respectively, the baseline regression is given by

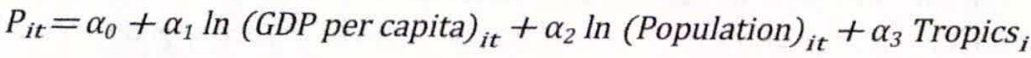

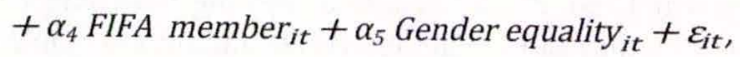

where $P_{i t}$ is one of the two outcome measures, FIFA points and Adjusted rank. GDP per

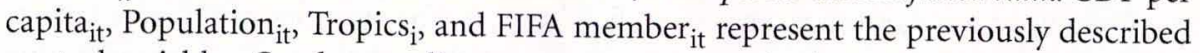
control variables. Gender equality $y_{\text {it }}$ represents our proxies for gender equality, the gender-specific labor force participation rate and life expectancy, respectively, and $\varepsilon_{i t}$ is a country-year-specific disturbance term.

As the performance of a country's national soccer team is influenced by a wide range of country-specific characteristics (e.g., the economic and environmental conditions, the institutional framework, and the affinity toward soccer), it is impossible to include all relevant impact factors in the estimation model. To address the problem of unobserved heterogeneity, we subsequently include year and country fixed effects in our estimations. Hence, our final specification in the first step is given by

$$
\begin{aligned}
P_{i t}= & \beta_{0}+\beta_{1} \ln (\text { GDP per capita })_{i t}+\beta_{2} \ln (\text { Population })_{i t}+\beta_{3} \text { Gender equality }_{i t} \\
& +\sum_{i=2}^{I} \delta_{i} c_{i}+\sum_{t=2}^{T} \lambda_{t} t_{t}+v_{i t}
\end{aligned}
$$

where $\sum \delta_{i} c_{i}$ represents a full set of country dummies and $\sum \lambda_{t} t_{t}$ is a full set of year dummies. By adding year and country fixed effects to the estimation model, we control for common year effects and for all time-constant, country-specific characteristics that affect the national team's soccer performance and might be correlated with gender equality (e.g., geographical conditions or a country's main religion). However, such an estimation approach is not able to control for unobservable time-variant country-specific factors, which might be correlated with both a country's soccer performance and its gender equality. Hence, ignoring this heterogeneity might lead to biased parameter estimates of our gender equality proxy variables.

In order to obtain an unbiased estimate of the effect of gender equality on the performance of a country's national soccer team, we pool the separate samples of male 
and female teams to one sample. We then use this pooled sample to estimate the following specification:

$$
\begin{aligned}
P_{i j t}= & \gamma_{0}+\gamma_{1} \text { Female }_{j}+\gamma_{2} \text { Gender equality }_{i j t}+\gamma_{3} \text { Female }_{j} \times \text { Gender equality }_{i j t} \\
& +\sum_{i=1}^{I} \sum_{t=1}^{T} \phi_{i t} c_{i} \times t_{t}+\zeta_{i j t}
\end{aligned}
$$

where $P_{i j t}$ represents the soccer performance measured by the Normalized FIFA points and the Adjusted rank, respectively, of country $i$, national team's gender $j$, in a given year $t$. To distinguish between male and female teams, we include an indicator variable Female $_{j}$ in our model. As we suspect the effects of the gender equality proxies on soccer performance to differ between men and women teams, we further include an interaction term between the Female dummy and the Gender equality proxies in the estimation equation. Finally, $\sum \sum \phi_{i t} c_{i} \times t_{t}$ represents a full set of country-year fixed effects and $\zeta_{i j t}$ is a country-gender-year-specific disturbance term.

The idea behind the inclusion of country-year fixed effects instead of separate country and year fixed effects is to net out all country-year specific factors that might be correlated with both a country's soccer performance and its degree of gender equality. Specifically, the country-year fixed effects include a separate fixed effect for every country-year cell. In doing so, they capture all observable and unobservable countryspecific characteristics. In contrast to Equation (2), this not only includes time-constant but also time-variant country-specific effects, as, for example, observable factors such as GDP per capita and unobservable factors such as changes in countries' political or institutional settings. To enable the estimation and identification of the regression parameters, all the explanatory variables included in Equation (3) have to vary within country-year cells (i.e., they have to vary by gender). Hence, the effect of gender equality on soccer performance obtained from Equation (3) is solely identified through variation in the respective outcome measure and LFPR and Life expectancy, respectively, between the male and the female soccer team within each country at a given point of time (i.e., within the country-year cell). Using this identification strategy enables us to control for any non-gender-specific heterogeneity that is correlated with the countries' soccer performances. As such, $\hat{\gamma}_{2}$ gives us an unbiased estimate of with the countries' soccer performances. As such, $\gamma_{2}$ gives us an unbiased estimate of
the effect of gender equality on a country's international soccer performance, while $\hat{\gamma}_{3}$ gives us an unbiased estimate of the difference in the importance of gender equality for the soccer performance of a country's male and female soccer team.

\section{Results}

The results of the single regressions for male and female soccer teams (Equations [1] and [2]) using FIFA points as an outcome measure are shown in Tables 2 and 3. While Table 2 includes the results using the gender-specific labor force participation rate as our proxy for gender equality, Table 3 includes those using life expectancy as a genderspecific control variable. In both cases, the first three columns show the results for women and the last three those for men. In each case, Column I includes no fixed effects whatsoever, Column II includes year fixed effects, and Column III contains both year and country fixed effects.

The results of our first model, excluding country and year fixed effects, reveal that the international success of both male and female soccer teams increases with their 
country's population size and wealth (i.e., an increase in both variables is associated with higher FIFA points), which is in line with the findings of previous literature (see, e.g., Hoffmann et al., 2006; Leeds and Leeds, 2009). For male teams, however, the effect of GDP per capita is smaller than for female teams and only significant at the $10 \%$ level when considering FLFP as our gender equality proxy (see Table 2). For male teams, the results further reveal an adverse effect of a tropic climate on international soccer performance, while the country's climate is not correlated with the success of female teams. For both male and female teams, the success in international soccer increases with the time the countries' teams have been a member of the FIFA, which proxies for the countries' affinity toward soccer.

With respect to our variables of main interest, the gender-specific labor force participation rates and life expectancies, we find large differences between male and female soccer teams. While women's FIFA points significantly increase with the country's female labor force participation rate (Table 2) and women's life expectancy (Table 3), no effect of these gender equality proxies on soccer performance is found for men. This is a first indicator that gender equality is an important determinant of women's soccer success but not of men's.

While the results are robust to the inclusion of year fixed effects (Columns II), they alter substantially when country fixed effects are added to the regressions (Columns III). As the country fixed effects capture all inter-country heterogeneity previously explained by GDP, population, and our gender equality proxies, these variables have

Table 2. The Effect of LFPR on FIFA Points by Gender

\begin{tabular}{|c|c|c|c|c|c|c|}
\hline & \multicolumn{3}{|c|}{ Women } & \multicolumn{3}{|c|}{ Men } \\
\hline & I & II & III & I & II & III \\
\hline \multirow[t]{2}{*}{ In (GDP per capit } & ita) $116.160^{* * *}$ & $120.068^{* * *}$ & $-83.984^{* *}$ & $28.121^{*}$ & $29.811^{*}$ & -20.601 \\
\hline & $(19.470)$ & $(19.453)$ & (33.272) & $(16.921)$ & $(17.031)$ & (76.537) \\
\hline \multirow[t]{2}{*}{ In (Population) } & $67.037^{* * *}$ & $66.946^{* * *}$ & 105.927 & $41.660^{\star * *}$ & $41.597^{\star * *}$ & $-410.746^{* *}$ \\
\hline & $(12.124)$ & (11.998) & $(94.383)$ & (11.943) & (11.963) & (169.988) \\
\hline \multirow[t]{2}{*}{ Tropics } & -58.369 & -50.938 & - & $-106.275^{\star *}$ & $-102.829^{* *}$ & - \\
\hline & $(37.583)$ & $(37.864)$ & & $(43.100)$ & $(43.484)$ & \\
\hline \multirow{2}{*}{$\begin{array}{l}\text { FIFA member } \\
\text { (in years) }\end{array}$} & $2.715^{* * *}$ & $2.737^{* * *}$ & - & $3.942^{* * *}$ & $3.955^{\star * *}$ & - \\
\hline & $(0.717)$ & $(0.713)$ & & $(0.633)$ & $(0.634)$ & \\
\hline \multirow[t]{2}{*}{ LFPR } & $3.696^{* * *}$ & $3.716^{* * *}$ & -0.014 & -2.944 & -2.921 & 3.707 \\
\hline & (1.195) & $(1.176)$ & (1.623) & $(1.993)$ & (1.988) & (4.105) \\
\hline \multirow{2}{*}{ Constant } & $-1117.330^{* * *}$ & ${ }^{*}-1061.556^{\star * *}$ & * 452.605 & -396.688 & -394.864 & $6884.263^{* * *}$ \\
\hline & (307.289) & $(304.420)$ & $(1532.220)$ & $(309.442)$ & (311.435) & (2579.594) \\
\hline Year FE & No & Yes & Yes & No & Yes & Yes \\
\hline Country FE & No & No & Yes & No & No & Yes \\
\hline Observations & 1,604 & 1,604 & 1,604 & 1,604 & 1,604 & 1,604 \\
\hline Clusters & 157 & 157 & 157 & 157 & 157 & 157 \\
\hline Adjusted $\mathrm{R}^{2}$ & 0.596 & 0.614 & 0.981 & 0.431 & 0.433 & 0.847 \\
\hline
\end{tabular}

Notes: Significant at ${ }^{\star * *} 1 \%$ level; ${ }^{\star *} 5 \%$ level; ${ }^{\star} 10 \%$ level. Robust standard errors (clustered at the country level) are reported in parentheses. The dependent variable is the average FIFA points for female and male national teams by year. 
Table 3. The Effect of Life Expectancy on FIFA Points by Gender

\begin{tabular}{|c|c|c|c|c|c|c|}
\hline & \multicolumn{3}{|c|}{ Women } & \multicolumn{3}{|c|}{ Men } \\
\hline & I & II & III & I & II & III \\
\hline ln (GDP per capit & $\begin{array}{c}\text { a) } 69.823^{* * *} \\
(26.725)\end{array}$ & $\begin{array}{c}74.186^{* * *} \\
(26.621)\end{array}$ & $\begin{array}{c}-84.644^{\star *} \\
(32.985)\end{array}$ & $\begin{array}{l}42.979^{* *} \\
(19.349)\end{array}$ & $\begin{array}{l}43.431^{* *} \\
(19.328)\end{array}$ & $\begin{array}{c}-8.291 \\
(77.743)\end{array}$ \\
\hline $\ln$ (Population) & $\begin{array}{c}66.504^{* * *} \\
(11.990)\end{array}$ & $\begin{array}{c}66.360^{* * *} \\
(11.875)\end{array}$ & $\begin{array}{c}98.884 \\
(101.846)\end{array}$ & $\begin{array}{c}39.332^{* * *} \\
(12.233)\end{array}$ & $\begin{array}{c}39.368^{* * *} \\
(12.268)\end{array}$ & $\begin{array}{c}-376.794^{* *} \\
(171.442)\end{array}$ \\
\hline Tropics & $\begin{array}{c}53.629 \\
(37.372)\end{array}$ & $\begin{array}{c}-46.315 \\
(37.692)\end{array}$ & - & $\begin{array}{c}-115.986^{* * *} \\
(42.198)\end{array}$ & $\begin{array}{c}-112.558^{* * *} \\
(42.530)\end{array}$ & - \\
\hline $\begin{array}{l}\text { FIFA member } \\
\text { (in years) }\end{array}$ & $\begin{array}{c}2.790^{* * *} \\
(0.686)\end{array}$ & $\begin{array}{c}2.820^{* * *} \\
(0.680)\end{array}$ & - & $\begin{array}{c}4.020^{* * *} \\
(0.708)\end{array}$ & $\begin{array}{c}4.021^{* * *} \\
(0.707)\end{array}$ & - \\
\hline Life expectancy & $\begin{array}{l}6.514^{\star \star} \\
(2.610)\end{array}$ & $\begin{array}{l}6.418^{\star *} \\
(2.590)\end{array}$ & $\begin{array}{c}0.847 \\
(3.512)\end{array}$ & $\begin{array}{c}-2.954 \\
(2.469)\end{array}$ & $\begin{array}{l}-2.729 \\
(2.448)\end{array}$ & $\begin{array}{l}-5.259 \\
(6.644)\end{array}$ \\
\hline Constant & $\begin{array}{c}-946.493^{* * *} \\
(281.207)\end{array}$ & $\begin{array}{c}-892.460^{* * *} \\
(279.308)\end{array}$ & $\begin{array}{c}509.129 \\
(1577.295)\end{array}$ & $\begin{array}{l}-527.727^{\star} \\
(297.377)\end{array}$ & $\begin{array}{l}-528.844^{*} \\
(299.870)\end{array}$ & $\begin{array}{l}6876.9399^{* * *} \\
(2608.260)\end{array}$ \\
\hline Year FE & No & Yes & Yes & No & Yes & Yes \\
\hline Country FE & No & No & Yes & No & No & Yes \\
\hline Observations & 1,604 & 1,604 & 1,604 & 1,604 & 1,604 & 1,604 \\
\hline Clusters & 157 & 157 & 157 & 157 & 157 & 157 \\
\hline Adjusted $\mathrm{R}^{2}$ & 0.584 & 0.602 & 0.981 & 0.429 & 0.432 & 0.847 \\
\hline
\end{tabular}

Notes: Significant at ${ }^{* * *} 1 \%$ level; ${ }^{* *} 5 \%$ level; ${ }^{*} 10 \%$ level. Robust standard errors (clustered at the country level) are reported in parentheses. The dependent variable is the average FIFA points for female and male national teams by year.

hardly any explanatory power once inter-country heterogeneity is accounted for. In some cases, the coefficients of GDP per capita and population even switch signs, suggesting that these variables are negatively correlated with international soccer success. While this result seems counter-intuitive at first sight, it can be explained by the fact that those countries that have shown the highest growth in population size and GDP over the time period considered, such as many African, South Asian, and South East Asian countries, are not among the traditional soccer nations, which are mainly found in Europe and South America. Overall, these results suggest that it is economic and cultural differences between countries rather than the current economic condition within a country that are able to explain variation in international soccer performance.

Tables 4 and 5 now show the respective results of Equations (1) and (2) using Adjusted rank as an outcome measure. Overall, the results are robust to the use of this alternative measures of soccer performance. Again, gender-specific LFPR and Life expectancy significantly increase the international soccer success of women, but not that of men. ${ }^{6}$ Once the country fixed effects are added to the model (Columns III), however, these variables have hardly any explanatory power for the international soccer performance of both men and women.

In order to gain deeper insight into the impact of gender equality on international soccer, regressions containing both male and female soccer teams are represented in Equation (3). In all regressions, country-year fixed effects are included, which requires 
Table 4. The Effect of LFPR on Adjusted FIFA Ranks by Gender

\begin{tabular}{|c|c|c|c|c|c|c|}
\hline & \multicolumn{3}{|c|}{ Women } & \multicolumn{3}{|c|}{ Men } \\
\hline & I & II & III & I & II & III \\
\hline \multirow{2}{*}{\multicolumn{2}{|c|}{$\begin{array}{r}\ln \left(\text { GDP per capita) } 12.778^{* * *}\right. \\
(2.472)\end{array}$}} & $-13.405^{* * *}$ & 2.464 & -2.895 & -3.451 & -8.895 \\
\hline & & $(2.449)$ & $(4.798)$ & $(2.473)$ & $(2.499)$ & $(8.537)$ \\
\hline ln (Population) & $\begin{array}{c}-7.411^{* * *} \\
(1.415)\end{array}$ & $\begin{array}{l}-7.398^{\star * *} \\
(1.391)\end{array}$ & $\begin{array}{c}14.853 \\
(15.292)\end{array}$ & $\begin{array}{l}-5.547^{* * *} \\
(1.585)\end{array}$ & $\begin{array}{l}-5.534^{* * *} \\
(1.581)\end{array}$ & $\begin{array}{c}25.485 \\
(18.668)\end{array}$ \\
\hline Tropics & $\begin{array}{l}8.224^{*} \\
(4.874)\end{array}$ & $\begin{array}{l}7.059 \\
(4.865)\end{array}$ & - & $\begin{array}{c}17.349^{* * *} \\
(6.083)\end{array}$ & $\begin{array}{c}16.321^{* * *} \\
(6.111)\end{array}$ & - \\
\hline $\begin{array}{l}\text { FIFA member } \\
\text { (in years) }\end{array}$ & $\begin{array}{c}-0.358^{* * *} \\
(0.094)\end{array}$ & $\begin{array}{c}-0.360^{* * *} \\
(0.093)\end{array}$ & - & $\begin{array}{c}-0.513^{* * *} \\
(0.089)\end{array}$ & $\begin{array}{c}-0.515^{* * *} \\
(0.089)\end{array}$ & - \\
\hline LFPR & $\begin{array}{l}0.342^{\star *} \\
(0.149)\end{array}$ & $\begin{array}{c}-0.343^{\star *} \\
(0.145)\end{array}$ & $\begin{array}{l}-0.039 \\
(0.271)\end{array}$ & $\begin{array}{c}0.469 \\
(0.292)\end{array}$ & $\begin{array}{c}0.469 \\
(0.287)\end{array}$ & $\begin{array}{l}-0.565 \\
(0.449)\end{array}$ \\
\hline Constant & $\begin{array}{l}342.891^{* * *} \\
(35.682)\end{array}$ & $\begin{array}{c}332.305^{* * *} \\
(35.167)\end{array}$ & $\begin{array}{l}-193.544 \\
(239.131)\end{array}$ & $\begin{array}{c}170.513^{* * *} \\
(40.813)\end{array}$ & $\begin{array}{l}160.587^{\star * *} \\
(40.476)\end{array}$ & $\begin{array}{l}-222.154 \\
(287.199)\end{array}$ \\
\hline Year FE & No & Yes & Yes & No & Yes & Yes \\
\hline Country FE & No & No & Yes & No & No & Yes \\
\hline Observations & 1,604 & 1,604 & 1,604 & 1,604 & 1,604 & 1,604 \\
\hline Clusters & 157 & 157 & 157 & 157 & 157 & 157 \\
\hline Adjusted $\mathrm{R}^{2}$ & 0.550 & 0.591 & 0.970 & 0.441 & 0.474 & 0.900 \\
\hline
\end{tabular}

Notes: Significant at ${ }^{* *} 1 \%$ level; ${ }^{* *} 5 \%$ level; ${ }^{*} 10 \%$ level. Robust standard errors (clustered at the country level) are reported in parentheses. The dependent variable is the adjusted FIFA ranking for female and male national teams by year.

Table 5. The Effect of Life Expectancy on Adjusted FIFA Ranks by Gender

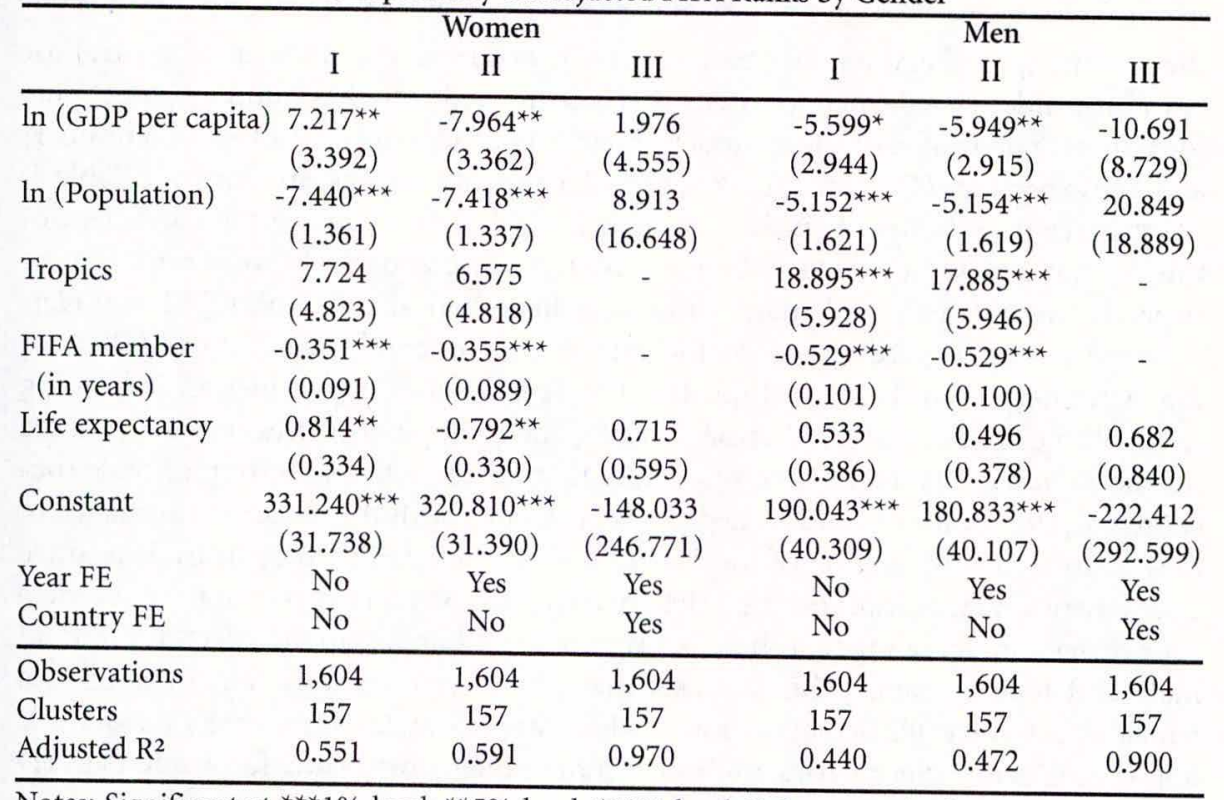

Notes: Significant at ${ }^{* * *} 1 \%$ level; ${ }^{* *} 5 \%$ level; ${ }^{\star} 10 \%$ level. Robust standard errors (clustered at the country level) are reported in parentheses. The dependent variable is the adjusted FIFA ranking for female and male national teams by year. 
Table 6. The Differential Effect of Gender Equality on the Strength of Male and Female National Teams

\begin{tabular}{|c|c|c|c|c|}
\hline & \multicolumn{2}{|c|}{ FIFA Points } & \multicolumn{2}{|c|}{ Adj. FIFA Ranks } \\
\hline & I & II & I & II \\
\hline Female & $\begin{array}{c}-0.065 \\
(0.060)\end{array}$ & $\begin{array}{c}-0.263^{\star * *} \\
(0.040)\end{array}$ & $\begin{array}{c}33.846^{* * *} \\
(9.104)\end{array}$ & $\begin{array}{c}63.794^{* * *} \\
(5.385)\end{array}$ \\
\hline LFPR & $\begin{array}{c}-0.001^{\star} \\
(0.001)\end{array}$ & - & $\begin{array}{l}0.292^{\star *} \\
(0.122)\end{array}$ & - \\
\hline Female $x$ LFPR & $\begin{array}{c}0.003^{\star * *} \\
(0.001)\end{array}$ & - & $\begin{array}{c}-0.475^{* * *} \\
(0.120)\end{array}$ & - \\
\hline Life expectancy & - & $\begin{array}{c}-0.003 \\
(0.002)\end{array}$ & - & $\begin{array}{c}-1.104^{\star * *} \\
(0.345)\end{array}$ \\
\hline Female $\mathrm{x}$ Life expectancy & - & $\begin{array}{c}0.005^{* * *} \\
(0.001)\end{array}$ & - & $\begin{array}{c}-0.798^{* * *} \\
(0.085)\end{array}$ \\
\hline Constant & $\begin{array}{c}0.476^{* * *} \\
(0.064)\end{array}$ & $\begin{array}{c}0.571^{* * *} \\
(0.162)\end{array}$ & $\begin{array}{c}45.222^{* * *} \\
(9.551)\end{array}$ & $\begin{array}{c}143.626^{* * *} \\
(23.515)\end{array}$ \\
\hline Country-year FE & Yes & Yes & Yes & Yes \\
\hline Observations & 3,208 & 3,208 & 3,208 & 3,208 \\
\hline Clusters & 1,604 & 1,604 & 1,604 & 1,604 \\
\hline Adjusted $\mathrm{R}^{2}$ & 0.566 & 0.586 & 0.668 & 0.695 \\
\hline
\end{tabular}

Notes: Significant at ${ }^{* * *} 1 \%$ level; ${ }^{* *} 5 \%$ level; ${ }^{*} 10 \%$ level. Robust standard errors (clustered at the country-year level) are reported in parentheses. The dependent variable is the normalized average FIFA points and the adjusted FIFA ranking, respectively, for female and male national teams by year.

the remaining explanatory variables to vary by gender and enables us to control for any non-gender-specific heterogeneity that is correlated with the countries' soccer performances. The results of these models, including gender-specific LFPR (Columns I) and Life expectancy (Columns II) as our gender equality proxies, are shown in Table 6.

As the Female dummy is interacted with LFPR (Life expectancy) the coefficient of this dummy shows the average difference in FIFA points and the Adjusted rank, respectively, between female and male teams at a hypothetical point of $L F P R=0$ (Life expectancy $=0) . ?$ Regarding our coefficients of main interest, the effect of LFPR (and Life expectancy) and its interaction with the Female dummy provides an interesting result. The coefficient of LFPR is negative for the FIFA points regression and positive for the Adjusted rank regression, suggesting that for the reference group of male soccer teams, the country's $L F P R$ is negatively correlated with the soccer performance of these teams. The interaction of the Female dummy and $L F P R$, in contrast, is positive and statistically significant for the FIFA points regression and negative for the Adjusted rank regression, revealing that there is a significant difference in the effect of LFPR on male and female teams. This suggests that within-country variation in male and female labor force participation rates, which approximates for women's economic opportunities in society, have significantly more explanatory power for women's international soccer performance than for men's. 
Based on these regression results, we further calculate the overall effect of our gender equality measure on the soccer performance of women. The effect of LFPR on women's Adjusted rank, for example, amounts to -0.184 with a standard error of 0.062 $(p$-value $=0.003)$. In terms of magnitude, this effect is non-negligible. A one standard deviation increase in $L F P R$, which is roughly equal to the difference in the female LFPR between Italy $(54.0 \%)$ and Russia $(68.8 \%)$ in 2014, improves the ranking by about three positions. This finding suggests that there is a positive and sizable effect of a country's female labor force participation rate on the international soccer performance of female teams, but no comparable effect for male teams.

To further illustrate the magnitude of the LFPR effect, Figure 4 shows the percentage change in the gap between the male teams' ranking position and the female teams' ranking position for the hypothetical situation of an equalization of the male and female labor force participation rate for the countries with the top five female teams in 2014 (left panel) as well as the five countries that would experience the largest

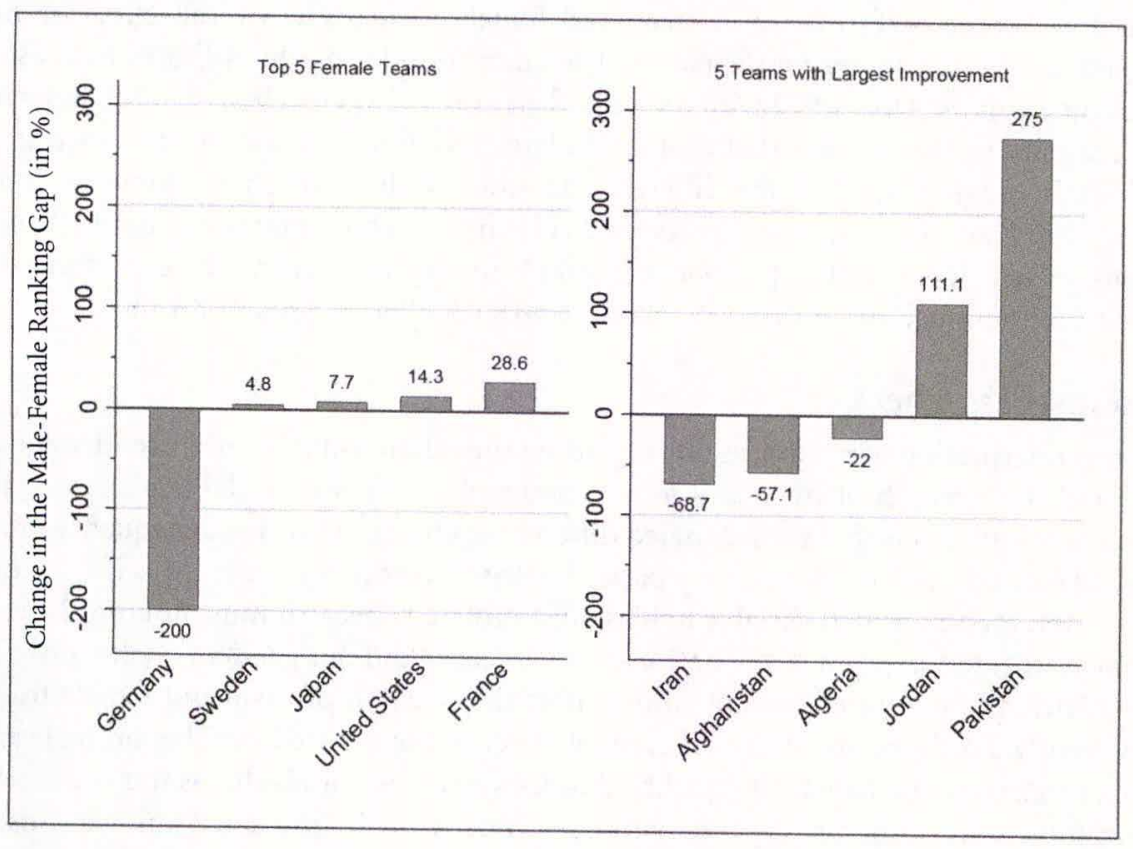

Figure 4. Hypothetical change in the male-female ranking gap in case of an equalization of the male and female LFPR.

Notes: The figure shows the percentage change in the gap between the male teams' ranking position and the female teams' ranking position for the hypothetical situation of an equalization of the male and female labor force participation rate. Negative values represent a closing of the male-female ranking gap while positive values represent a widening of the male-female ranking gap in favor of the female team. The illustration covers the countries with the top five female teams in 2014 (left panel) as well as the five countries that would experience the largest improvement in the female team's ranking position in 2014 (right panel). 
improvement in the female team's ranking position in 2014 (right panel). Our results suggest that for France, for example, an increase in the female LFPR to the level of the male LFPR would improve the female position by two positions, improving from a rank of four to two. Given an initial positive gap between the male and female position of seven positions, this represents an increase in the male-female ranking gap by $28.6 \%$. For Iran, on the other hand, an equalization of the male and the female LFPR would improve the female rank by 11 positions, and reduce the former negative gap between the male and the female ranking (position 35 vs. position 51 ) by $68.7 \%$.

The results for our second gender equality measure, life expectancy at birth, are similar to those of LFPR. For male teams, Life expectancy is uncorrelated with their international soccer performance as measured by FIFA points, while it is significantly negatively correlated with the Adjusted rank. The interaction of Life expectancy with the Female dummy, in contrast, is positive and highly statistically significant for the FIFA points regression and negative and highly significant for the Adjusted rank regression, again suggesting that our gender equality proxy has a diverse effect on the international soccer performance of male and female teams. The overall effect of Life expectancy on the soccer performance of women considering the Adjusted rank as an outcome amounts to -1.902 with a standard error of $0.299(p$-value $=0.000)$. In terms of magnitude, this implies that a one standard deviation increase in Life expectancy, which is roughly equal to the difference in women's life expectancy between India ( 68.5 years) and Hungary (78.7 years) in 2014, improves the ranking by about 19 positions. Hence, there exists a positive and sizable impact of women's life expectancy on their international soccer performance, but no such effect is present for men.

\section{Robustness Checks}

When interpreting our main results regarding the relationship between gender equality and the strength of male and female national soccer teams (Table 6), a possible source of concern is that the estimated differential effects of our gender equality proxies, LFPR and Life expectancy, may partly be driven by other country-specific factors. However, for an omitted variable to bias our estimated effects, it must not only be correlated with the strength of the national soccer teams and our gender equality proxies. In addition, the omitted variable must affect the strength of male and female teams differently. Furthermore, if the differential effect of the omitted variable on male and female teams is due to gender equality, this does not bias our results, as this is the relationship we are aiming to capture with our gender equality proxies. Thus, we consider problems resulting from omitted factors to be of minor relevance for the identification of our main results.

However, to ensure the robustness of our main results shown in Table 6, we conduct a number of sensitivity checks. First, we follow Gelade and Dobson (2007), who in their analysis average each country's FIFA rating over all periods to examine stable structural influences on national team strength. In doing so, we re-estimate our main model using average values over the sample period 2003-2014 for our outcome and explanatory variables. To make the average values comparable and adjust for the impact of teams with only a few observations, we include only countries that appear both with their male and female teams for at least five years in the FIFA Ranking. Applying these restrictions and taking the average over all years, our sample is reduced 
Table 7. Robustness with Respect to the Outcome Variable, the Gender Equality Proxies, and Influential Observations

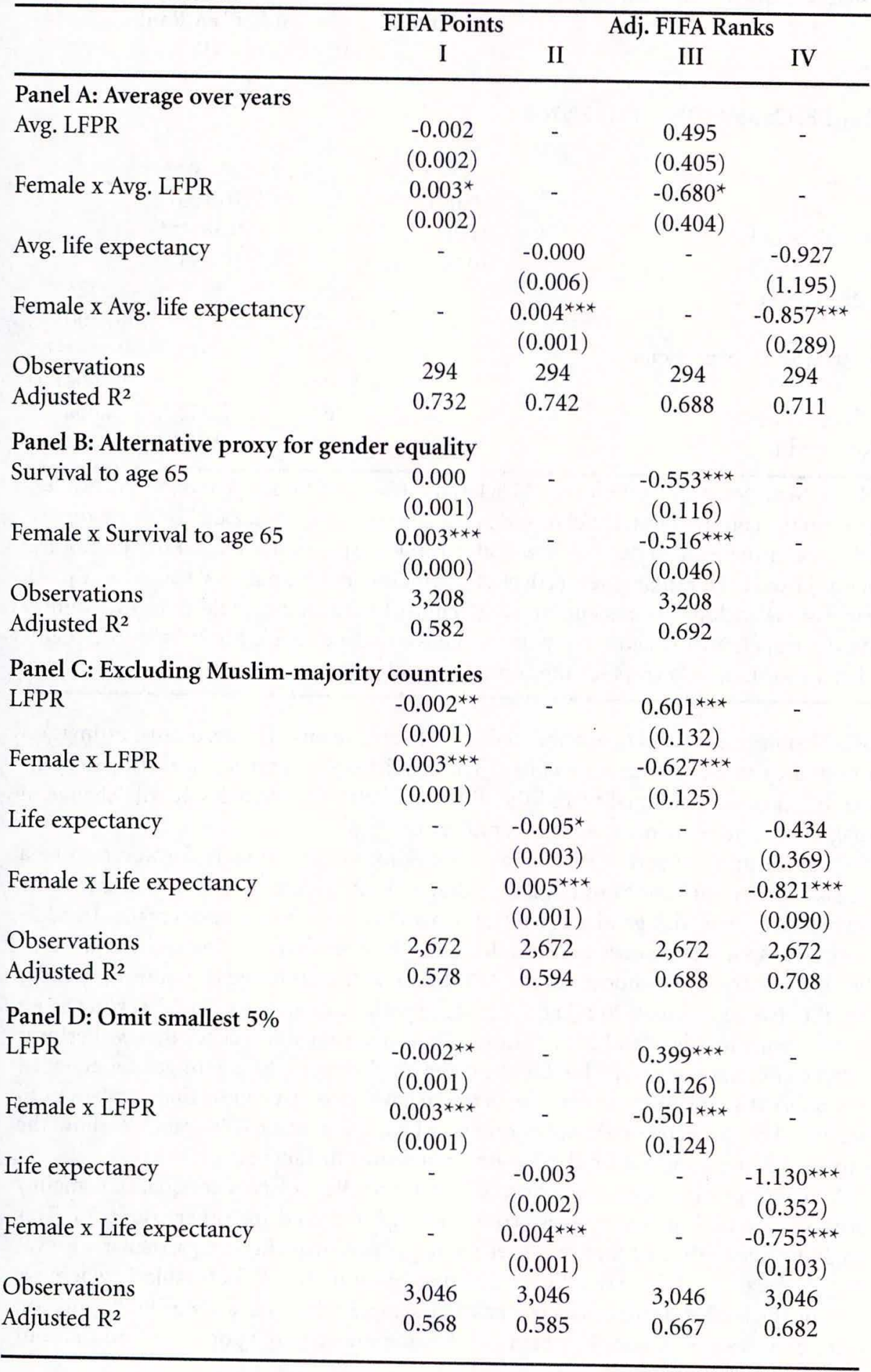


Table 7. Robustness with Respect to the Outcome Variable, the Gender Equality Proxies, and Influential Observations, continued

\begin{tabular}{|c|c|c|c|c|}
\hline & \multirow{2}{*}{$\begin{array}{c}\text { FIFA Points } \\
\text { I }\end{array}$} & \multicolumn{3}{|c|}{ Adj. FIFA Ranks } \\
\hline & & II & III & IV \\
\hline \multicolumn{5}{|c|}{ Panel E: Omit if $\mid$ DFBETA $\mid>2 / \sqrt{\mathrm{N}}$} \\
\hline LFPR & $\begin{array}{c}-0.001 \\
(0.001)\end{array}$ & - & $\begin{array}{c}0.346^{* * *} \\
(0.100)\end{array}$ & - \\
\hline Female $\mathrm{x}$ LFPR & $\begin{array}{c}0.002^{* * *} \\
(0.001)\end{array}$ & - & $\begin{array}{c}-0.581^{* * *} \\
(0.094)\end{array}$ & - \\
\hline Life expectancy & - & $\begin{array}{c}0.001 \\
(0.002)\end{array}$ & - & $\begin{array}{c}-1.372^{\star * *} \\
(0.300)\end{array}$ \\
\hline Female $x$ Life expectancy & - & $\begin{array}{c}0.004^{* * *} \\
(0.000)\end{array}$ & - & $\begin{array}{c}-0.537^{* * *} \\
(0.064)\end{array}$ \\
\hline Observations & 2,824 & 2,762 & 2,818 & 2,862 \\
\hline Adjusted R² & 0.670 & 0.685 & 0.760 & 0.772 \\
\hline
\end{tabular}

Notes: Significant at ${ }^{* * *} 1 \%$ level; ${ }^{* *} 5 \%$ level; ${ }^{*} 10 \%$ level. Robust standard errors (clustered at the country level, Panel A, and at the country-year level, Panel B-E) are reported in parentheses. The dependent variable is the normalized average FIFA points and the adjusted FIFA ranking, respectively, for female and male national teams by year. All regressions include a constant, and our control variables: Female dummy, country fixed effects (Panel A), country-year fixed effects (Panel B-E). For brevity, the coefficients and standard errors for the control variables are not reported.

to 294 observations, 147 each for male and female teams. The respective estimation results are shown in Panel A of Table 7. The coefficients of interest, measuring the general effect of gender equality and the differential effect for females, hardly change in magnitude and remain statistically significant. ${ }^{8}$

One can think of several alternative proxies for gender equality. However, to be a suitable proxy variable in our research design, such a variable not only needs to be highly correlated with gender equality, but also vary over males and females. In addition, time series data needs to be available for the considered period for a large number of countries. We choose to use LFPR as a well-established measure for gender equality (see, e.g., Klein, 2004) and introduce with our second proxy Life expectancy a new measure to this strand of literature. The second robustness check that we perform is to ensure that our results hold when using an alternative proxy for gender equality. The alternative measure we consider is the survival rate of a cohort that survives until age $65 .^{9}$ The respective estimation results, which are presented in Panel B, show the expected pattern and are similar to our main results in Table 6.

A further possible source of concern is that the effect of gender equality is mainly driven by some Muslim-majority countries and not valid for other countries. This might be due to the fact that issues related to gender inequality are particularly prevalent in these countries. We address this possibility in Panel C of Table 7, where we exclude those 32 countries from our baseline sample, which have a Muslim population share of at least $50 \%$ (i.e., in which Islam is the majority religion). We find that our 
main results from Table 6 are highly robust to excluding these countries. The estimated coefficients are remarkably similar in terms of magnitude and significance, providing evidence for the general validity of our results.

Next, we check whether the results from Table 6 are driven by some particularly influential outliers. In the scatter plots of the raw data in Figure 3, which show the relationship between the female teams' FIFA points and the female labor force participation rates (top left panel) and life expectancies (bottom left panel), respectively, a number of observations appear as outliers in terms of their female labor force participation rate and life expectancy, respectively. The fourth robustness check that we perform, therefore, tests whether our results are sensitive to excluding $5 \%$ of the countries with the smallest female labor force participation rates and life expectancies, respectively, from the sample. The results, presented in Panel D, show that our main results remain unchanged.

Finally, in Panel E, we consider a more systematic approach to detect influential observations and compute the DFBETA statistic. ${ }^{10}$ Following Belsley et al. (1980), we omit all observations for which $\mid$ DFBETA $_{i} \mid>2 / \sqrt{N}$, where $N$ is the number of observations. Our main results are, once again, robust.

To summarize, we find that the estimated differential effects of our gender equality proxies for male and female teams presented in Table 6 are very robust to various sensitivity analyses. In all five robustness checks the coefficients of the interaction terms show the expected signs, are stable in magnitude, and remain statistically significant, confirming the existence of a differential effect of gender equality on the strength of male and female national soccer teams.

\section{Conclusion}

In this article, we analyze the effect of gender equality on the performance of male and female national soccer teams. Given that soccer is played at a professional level all over the world and has the highest global television audience in sports (FIFA, 2010), a large and growing body of literature is concerned with the determinants of the international performance of national soccer teams.

While most authors examine the determinants of the international soccer performance of male teams (e.g., Hoffmann et al., 2002; Leeds and Leeds, 2009), only a few are specifically interested in the factors influencing women's success (e.g., Torgler, 2008; Cho, 2013). These studies show that the international success of female soccer teams is positively correlated with women's economic opportunities and political rights in their country. However, as they are not able to control for all relevant impact factors, the identified associations might be biased by unobservable country-specific characteristics that affect both female soccer performance and women's empowerment.

In this article, we propose an estimation strategy that uses the variation in the performance between the female and the male national soccer team within each country to identify an unbiased effect of gender equality on women's international soccer performance. By applying this strategy, it is possible to include country-year fixed effects into the estimation model and thus control for any country-specific factors that potentially bias the estimation results. In particular, we are interested in whether withincountry variation in labor force participation rates and life expectancies between the genders, which serve as measures for the country's gender equality, are able to explain 
differences in the international soccer performance of the male and female national team within a given country.

In accordance with previous literature on international soccer performance, we find the countries' GDP per capita and population size to be positively associated with women's and men's international soccer performance. These effects diminish, however, once country fixed effects are included in the model. With respect to our measures of gender equality, the results differ largely between male and female soccer teams.

In separate regressions for male and female soccer teams, we find the gender-specific labor force participation rate and the life expectancy at birth to be positively correlated with women's international soccer performance, but uncorrelated with men's performance. This is a first indicator of the differential importance of gender equality for men's and women's success in international soccer. More importantly, the results of our main estimations, which solely uses variation between male and female national teams within a given country at a given point of time to identify the effect of gender equality on international soccer performance, support this result. The estimates reveal that within-country differences in male and female labor force participation rates and life expectancies explain the international soccer performance of female teams, but have no notable explanatory power for the success of male teams. To ensure the robustness of these results, we conduct various sensitivity analyses. The results confirm that our estimates for the differential effect of gender equality on the strength of male and female national soccer teams are remarkably robust. Our analysis therefore suggests that gender equality is an important determinant of female success-presumably not only in sports, but also in other fields of society.

\section{References}

Belsley, D. A., Kuh, E., \& Welsch, R. E. (1980). Regression diagnostics: Identifying influential data and sources of collinearity. Hoboken, $\mathrm{NJ}$ : John Wiley.

Bernard, A. B., \& Busse, M. R. (2004). Who wins the Olympic Games: Economic resources and medal totals. The Review of Economics and Statistics, 86, 413-417.

Bredtmann, J., Crede, C. J., \& Otten, S. (2016). Participation and success at the Olympic Games - The role of gender equality. Working paper.

Cho, S.-Y. (2013). A league of their own: Female soccer, male legacy and women's empowerment. DIW Discussion Paper No. 1267.

Doepke, M., Tertilt, M., \& Voena, A. (2012). The economics and politics of women's rights. Annual Review of Economics, 4, 339-372.

Duflo, E. (2012). Women empowerment and economic development. Journal of Economic Literature, 50, 1051-1079.

FIFA. (2007). FIFA big count 2006: 270 million people active in football. Retrieved from http://www.fifa. com/mm/document/fifafacts/bcoffsurv/bigcount.statspackage\%5f7024.pdf

FIFA. (2010). 2010 FIFA World Cup South Africa: Television audience report. Retrieved from http://resources.fifa.com/mm/document/affederation/tv/01/47/32/73/2010fifaworldcupsouthafricatvaudiencereport.pdf

Gallup, J. L., Mellinger, A. D., \& Sachs, J. D. (2010). Geography datasets. Harvard Dataverse, V1. Retrieved from http://hdl.handle.net/1902.1/14429

Gelade, G. A., \& Dobson, P. (2007). Predicting the comparative strengths of national football teams. Social Science Quarterly, 88, 244-258.

Hoffmann, R., Chew Ging, L., Matheson, V., \& Ramasamy, B. (2006). International women's football and gender inequality. Applied Economics Letters, 13, 999-1001. 
Hoffmann, R., Chew, G., \& Ramasamy, B. (2002). The socio-economic determinants of international soccer performance. Journal of Applied Economics, 5, 253-272.

Hoffmann, R., Chew, G., \& Ramasamy, B. (2004). Olympic success and ASEAN countries: Economic analysis and policy implications. Journal of Sports Economics, 5, 262-276.

Johnson, D. K. N., \& Ali, A. (2004). A tale of two seasons: Participation and medal counts at the summer and winter Olympic Games. Social Science Quarterly, 85, 974-993.

Klein, M. W. (2004). Work and play: International evidence of gender equality in employment and sports. Journal of Sports Economics, 5, 227-242.

Leeds, E. M., \& Leeds, M. A. (2009). International soccer success and national institutions. Journal of Sports Economics, 10, 369-390.

Leeds, E. M., \& Leeds, M. A. (2012). Gold, silver, and bronze: Determining national success in men's and women's summer Olympic events. Journal of Economics and Statistics, 232, 279-292.

Lowen, A., Deaner, R. O., \& Schmitt, E. (2016). Guys and gals going for gold: The role of women's empowerment in Olympic success. Journal of Sports Economics, 17, 260-285.

Macmillan, P., \& Smith, I. (2007). Explaining international soccer rankings. Journal of Sports Economics, 8, 202-213.

Matheson, V. A., \& Congdon-Hohman, J. (2011). International women's soccer and gender inequality: Revisited. College of the Holy Cross, Department of Economics Faculty Research Series, Paper No. 11-07.

NBC. (2015). Super Bowl XLIX on NBC is most-watched show in U.S. television history. Retrieved from http://nbcsportsgrouppressbox.com/2015/02/02/super-bowl-xlix-on-nbcis-most-watched-show-in-u-s-television-history/

Rogers, S. (2014). Insights into the \#WorldCup conversation on Twitter. https://blog.twitter.com/2014/insights-into-the-worldcup-conversation-on-twitter

Sachs, J. D. (2001). Tropical underdevelopment. NBER Working Paper No. 8119.

Torgler, B. (2004). The economics of the FIFA Football Worldcup. Kyklos, 57, 287-300.

Torgler, B. (2008). The determinants of women's international soccer performances. International Journal of Sport Management and Marketing, 3, 305-318.

Trivedi, P. K., \& Zimmer, D. M. (2014). Success at the summer Olympics: How much do economic factors explain? Econometrics, 2, 169-202.

United Nations. (2015). Transforming our World: The 2030 Agenda for Sustainable Development. https://sustainabledevelopment.un.org/content/documents/21252030\%20 Agenda\%20for\%20Sustainable\%20Development\%20web.pdf

\section{Endnotes}

${ }^{1}$ The FIFA World Cup further plays a huge role in the social media. During the 2014 tournament, 672 million tweets related to the World Cup were posted on Twitter. Of these tweets, 35.6 million were sent only during the semifinal between Brazil and Germany-a new Twitter record for a single event (Rogers, 2014).

${ }^{2}$ See http://www.fifa.com/fifa-world-ranking for further information on the FIFA World Ranking as well as Leeds and Leeds (2009) for a more extensive description of the calculation of this ranking.

${ }^{3}$ While FIFA points are available on a monthly basis, we aggregate the monthly scores to average yearly scores in our analysis.

${ }^{4}$ Further information and the underlying data of the Gender Inequality Index (GII) are available on the website of the UN Human Development Report; see http://hdr.undp.org/en/content/gender-inequality-index-gii 


\section{Bredtmann, Crede, Otten}

${ }^{5}$ While it is possible to control for additional country-specific indicators partly referred to in the literature, including further variables leads to the problem of multicollinearity between the explanatory variables and hinders the identification of fundamental underlying processes in the analysis. Therefore, we limited the regressors to those variables mentioned above, which represent a selection of variables controlling for a large variety of different sources of international sports success.

${ }^{6}$ Note that better soccer performance is associated with smaller ranks, such that negative coefficients represent a positive effect of the respective variable on a team's performance.

${ }^{7}$ As we calculated a new ranking based only on those countries that participate with both male and female soccer teams in any given year, there is actually no difference in the average rank of male and female teams in our sample (see Table 1).

${ }^{8}$ For brevity, we report only the coefficients of main interest. The full results are available upon request.

${ }^{9}$ A detailed description of the variable and its data source can be found in Table A1.

${ }^{10}$ The DFBETA statistic measures the difference in the estimated coefficient for the LFPR interaction and the life expectancy interaction, respectively, scaled by the respective standard error, when the observation $i$ is included and when it is excluded from the estimation.

\section{Authors' Note}

The authors are grateful to Thomas Bauer, the participants at the 7th ESEA Conference on Sports Economics, and an anonymous reviewer for helpful comments and suggestions. All remaining errors are our own.

\section{Appendix}

Table A1. Data Sources and Definition of Variables

\begin{tabular}{lll}
\hline Variable & Source & Description \\
\hline FIFA points & FIFA & $\begin{array}{l}\text { Points awarded to male and female national } \\
\text { teams based on the results of their } \\
\text { international matches to calculate the FIFA } \\
\text { World Ranking. }\end{array}$ \\
Normalized FIFA points & FIFA & $\begin{array}{l}\text { Unity-based normalization of the FIFA } \\
\text { points that transforms all values to fit into a } \\
\text { nationally common scale with the range [0,1]. }\end{array}$ \\
& FIFA & $\begin{array}{l}\text { New ordered ranking restricted to nations } \\
\text { that compete with both male and female } \\
\text { Adjusted Rank }\end{array}$ \\
& $\begin{array}{l}\text { teams in international soccer competitions } \\
\text { in a given year. The ranking is constructed } \\
\text { based on the teams' points in the FIFA } \\
\text { World Ranking. The first ranking position is } \\
\end{array}$ \\
& $\begin{array}{l}\text { assigned to the best performing team, i.e., } \\
\text { the team with the highest number of points } \\
\text { in a given year. }\end{array}$ \\
\hline
\end{tabular}


Table A1. Data Sources and Definition of Variables, continued

\begin{tabular}{|c|c|c|}
\hline Variable & Source & Description \\
\hline ln (GDP per capita) & World Bank & $\begin{array}{l}\text { Logarithm of GDP per capita (PPP, current } \\
\text { international \$). }\end{array}$ \\
\hline $\ln$ (Population) & World Bank & Logarithm of a country's population size. \\
\hline Tropics & Gallup et al. (2010) & $\begin{array}{l}\text { Data derived from the geography data sets. } \\
\text { The indicator variable marks countries with } \\
50 \% \text { or more of the population living in a } \\
\text { region with tropical or subtropical climate. }\end{array}$ \\
\hline FIFA member (in yea & ars) FIFA & $\begin{array}{l}\text { Number of years since a nation's soccer } \\
\text { association has become a FIFA member. }\end{array}$ \\
\hline LFPR & World Bank & $\begin{array}{l}\text { Labor force participation rate is the } \\
\text { proportion of the population aged 15-64 } \\
\text { that is economically active, i.e., all people } \\
\text { who supply labor for the production of } \\
\text { goods and services during a specified } \\
\text { period. Definition according to the } \\
\text { International Labour Organization (ILO). } \\
\text { This variable is gender-specific. }\end{array}$ \\
\hline Life expectancy & World Bank & $\begin{array}{l}\text { Life expectancy at birth indicates the } \\
\text { number of years a newborn infant would } \\
\text { live if prevailing patterns of mortality at the } \\
\text { time of its birth were to stay the same } \\
\text { throughout its life. This variable is gender- } \\
\text { specific. }\end{array}$ \\
\hline Survival to age 65 & World Bank & $\begin{array}{l}\text { Survival to age } 65 \text { refers to the percentage of } \\
\text { a cohort of newborn infants that would } \\
\text { survive to age } 65 \text {, if subject to current age- } \\
\text { specific mortality rates. This variable is } \\
\text { gender-specific. }\end{array}$ \\
\hline
\end{tabular}


Copyright of International Journal of Sport Finance is the property of Fitness Information Technology, Inc. and its content may not be copied or emailed to multiple sites or posted to a listserv without the copyright holder's express written permission. However, users may print, download, or email articles for individual use. 